\title{
The role of ozone in the treatment of the acute phase of ischemic heart disease
}

\author{
Stefano Ciampa, ${ }^{1}$ Giovanni Dequerquis, ${ }^{1}$ Biagio Lettieri ${ }^{2}$ \\ 1 Medical Surgeon, Specialist in Anesthesia, Resuscitation, Intensive Care and Pain Therapy; \\ ${ }^{2}$ Formerly Full Professor, Department of Anesthesiologic, Surgical Emergency Sciences, Second \\ University of Naples, Naples, Italy
}

\begin{abstract}
The present paper describes the role of ozone in the treatment of the acute phase of ischemic heart disease. Two studies are presented: the first mechanically induced myocardial ischemia in rats; the second involved 42 consecutive patients with an outcome comparable to the UA/non- $Q$ wave NSTEMI AMI group of the ENACT study, divided randomly into 2 groups with homogeneous quantitative levels (NYHA class II-III) and was evaluated at weeks 8 and 12 of treatment with ozone. Both studies confirm that i) the effectiveness of ozone therapy increases in relation to how early and how long treatment is performed; and ii) that ozone reduces the relative risk both of ischemic (infarct extension) and arrhythmia complications.
\end{abstract}

\section{Introduction}

An experimental study of murine samples involved a control group and a second group in which myocardial ischemia was mechanically induced by ligation, maintained for 25 minutes, of the left anterior descending coronary artery of the left ventricle. Subsequently, the process of reperfusion of the area was immediately begun for an additional 120 minutes.

Sixty minutes before ischemia/reperfusion was induced, the rats in the second group were pre-treated with a mixture of oxygen-ozone by

Correspondence: Biagio Lettieri, Scientific Society of Oxygen-Ozone Therapy, via Roma 69 , Gorle (BG), Italy.

Tel/Fax: +39.035.300903.

E-mail: biagio.lettieri@unina2.it

Key words: Ozone; Acute phase; Ischemic heart disease.

Received for publication: 16 November 2016.

Accepted for publication: 14 December 2016.

(C) Copyright S. Ciampa et al., 2016

Licensee PAGEPress, Italy

Ozone Therapy 2016; 1:6549

doi:10.4081/ozone.2016.6549

This article is distributed under the terms of the Creative Commons Attribution Noncommercial License (by-nc 4.0) which permits any noncommercial use, distribution, and reproduction in any medium, provided the original author(s) and source are credited. intraperitoneal delivery (Figure 1). The mean arterial blood pressure was recorded at the times shown in Figure 1.

The following calculations were made for the animals immediately after sacrifice: the extension of the necrotic tissue in relation to the muscle mass of the area at risk, expressed as a \% (ISLV) relative to the total weight of the left ventricle (ISLV/non-ischemic myocardium).

The area at risk was demonstrated using Evans Blue dye and the infarct size was shown with NBT staining. With regard to function, the entities of the following parameters were evaluated: oxidative stress, using nitrotyrosine which is known to be the most specific marker of peroxynitrite; the extent of the inflammation, using the CD68 cluster of differentiation which is specific for macrophage activity; immune status, using CD4 and CD8 which are specific for lymphocyte activity; of the apoptotic cells by assaying the activity of the caspase 3 proteases, which are known to be cell death modulators.

A comparative evaluation of the biological samples of the infarcted myocardial tissue from the control group $v s$ the group of rats which was pre-treated with ozone showed that nitrotyrosine precipitated less intensely in the infarcted heart + ozone (Figure 2). Figure 3 also shows that the activity of caspase 3 (an indicator of cell apoptosis) is reduced by pre-treatment with ozone; the same behavior is seen following the comparative assessment of the infarcted myocardial tissue from the two groups in Figure 4 with regards to macrophage (CD 68) and lymphocyte (CD 4; CD8) activity. ${ }^{2}$

The experimental study presented shows that ozone is capable of significantly reducing infarct extension in mice (Figure 5).

A survey of the most recent and accredited literature confirms that the oxygen-ozone mixture has also been used in humans in the treatment of cardiovascular diseases and in particular in cardiac-output, ${ }^{3}$ on hematology parameters, ${ }^{4}$ on the reperfusion of organs and systems. . $^{5}$

However, to date, no study has been able to convincingly correlate the therapeutic efficacy of the oxygen-ozone mixture with the prevention, or at least reduction, of the myocardial damage that follows each ischemic event: the reduction of the area at risk in the early phase of acute myocardial infarction (AMI) and on the eradication of arrhythmia, which is the leading cause of death in the first hour following an AMI.

Our experience is prompted by a pan-European survey of acute coronary syndromes, ${ }^{10-12}$ which is significantly due to the number of patients: 3092 enrolled cases in 17 European countries. The ENACT study has also revealed that chest pain was found to be caused: by unstable angina (UA) in $45 \%$ of cases; by non- $Q$ wave NSTEMI AMI in $15 \%$ of cases; by Q-wave transmural AMI in $39 \%$ of cases.

During the follow-up performed at 8 months after the termination of the ENACT study, it was observed that $9 \%$ of the entirety of the two groups defined in the ENACT study as unstable angina (UA) and as non- $Q$ wave NSTEMI AMI and which was $62 \%$ of the enrolled popula- 
tion and were stratified as medium-low risk and therefore treated with standard drug therapy, without using an invasive approach (aorto-coronary bypass) or a mini-invasive one (angioplasty) with thrombolysis, evolved towards overt myocardial infarction (QT-AMI).

Some authors agree on the hypothesis that this unfavorable consequence could be influenced by the compressive action of the perifocal edema around the area of necrosis, the extension of which is favored by oxidative stress (ROS) and the synthesis and release of mediators of reactive inflammation (cytokines) into the bloodstream. This mechanism is the cause of the prolongation of the ischemia of the myocardial tissue, which in turn facilitates the recurrence of necrosis in the same tissue and infarct extension.

Myocardial ischemia is the cause of cellular electrical instability, causes QT prolongation and causes severe arrhythmia. Clinical evidence and authoritative literature document the existence of a direct correlation between QT prolongation and arrhythmia that can lead to sudden death.

Taking action as early as possible on the myocardial territory surrounding the area of necrosis and which is characterized by an extensive area of edema, in turn surrounded by a wider zone of ischemia, may be a winning therapeutic strategy in preventing extension of AMI stratified as having a low-risk prognosis quoad vitam (61\%).

The design of the study conducted at the Second University of Naples Resuscitation Unit was prospective, double-blind with parallel groups of 42 consecutive patients with an outcome comparable to the UA/non- $Q$ wave NSTEMI AMI group of the ENACT study, divided randomly into 2 groups with homogeneous quantitative levels (NYHA class II-III) and was evaluated at weeks 8 and 12 of treatment with ozone (Tables 1-3).

The $\mathrm{S}$ Group made use of traditional standard therapy consisting of: analgesics, $\mathrm{O}_{2}$ therapy by nasal inhalation, heparin/LMWH, antiaggregant drugs, $\beta$-blockers, calcium channel blockers, nitrates and statins. In the $\mathrm{O}_{3}$ group, treatment with a mixture of $\mathrm{O}_{2}-\mathrm{O}_{3}$ was added to the abovementioned standard therapy.

The primary endpoint was to verify the effectiveness of ozone on recovery in the acute phase of AMI, the hypoperfused area of risk (ischemic penumbra) by myocardial scintigraphy.

The secondary endpoint used QTc analysis to verify the effectiveness of ozone in the control of arrhythmia. The patients were monitored using Holter ECG and the analysis concerned ECG tracings recorded 60 minutes before and after autotransfusion with ozone.

The QT interval was measured every 10 minutes, its correction relative to the heart rate was obtained using Bazett's formula: QTC $=Q R S / R R$. Myocardial scintigraphy before and after ozone treatment: at $\mathrm{T}_{0}$ and at the $12^{\text {th }}$ week of treatment.
Table 1. Patients' overview.

\begin{tabular}{lcc} 
& $\mathrm{S}$ & $\mathrm{O}_{3}$ \\
Patients (n) & 22 & 20 \\
M:F & $16: 4$ & $18: 4$ \\
\hline Age year (mean) & 57.7 & 57.7 \\
Hours from pain onset & 6.4 & 6.4 \\
\hline Previous AMI & 3 & 4 \\
Previous CABG & 2 & 2 \\
\hline
\end{tabular}

M, male; F, female; AMI, acute myocardial infarction; $\mathrm{CABG}$, coronary artery bypass graft.

Table 2. Analysis of efficacy results on short-term complications $\left(8^{\text {th }}\right.$ week $)$.

\begin{tabular}{lll} 
& $\mathrm{S}$ & $\mathrm{O}_{3}$ \\
CV death & 1 & 0 \\
Q-wave AMI & 3 & 1 \\
\hline Arrhythmia & 8 & 3 \\
Vagal stimulation & 0 & 5 \\
\hline PCI/PTCA & 1 & 1 \\
\hline
\end{tabular}

CV, cardiovascular; AMI, acute myocardial infarction; PCI/PTCA, percutaneous coronary intervention/ percutaneous transluminal coronary angioplasty.

Table 3. Analysis of efficacy results on long-term complications (12 ${ }^{\text {th }}$ week).

\begin{tabular}{lll} 
& $\mathrm{S}$ & $\mathrm{O}_{3}$ \\
CV death & 0 & 0 \\
Q-wave AMI & 4 & 1 \\
\hline Arrhythmia & 4 & 2 \\
Vagal stimulation & 0 & 8 \\
\hline PCI/PTCA & 1 & 1 \\
\hline
\end{tabular}

$\mathrm{CV}$, cardiovascular; AMI, acute myocardial infarction; PCI/PTCA, percutaneous coronary intervention/ percutaneous transluminal coronary angioplasty.

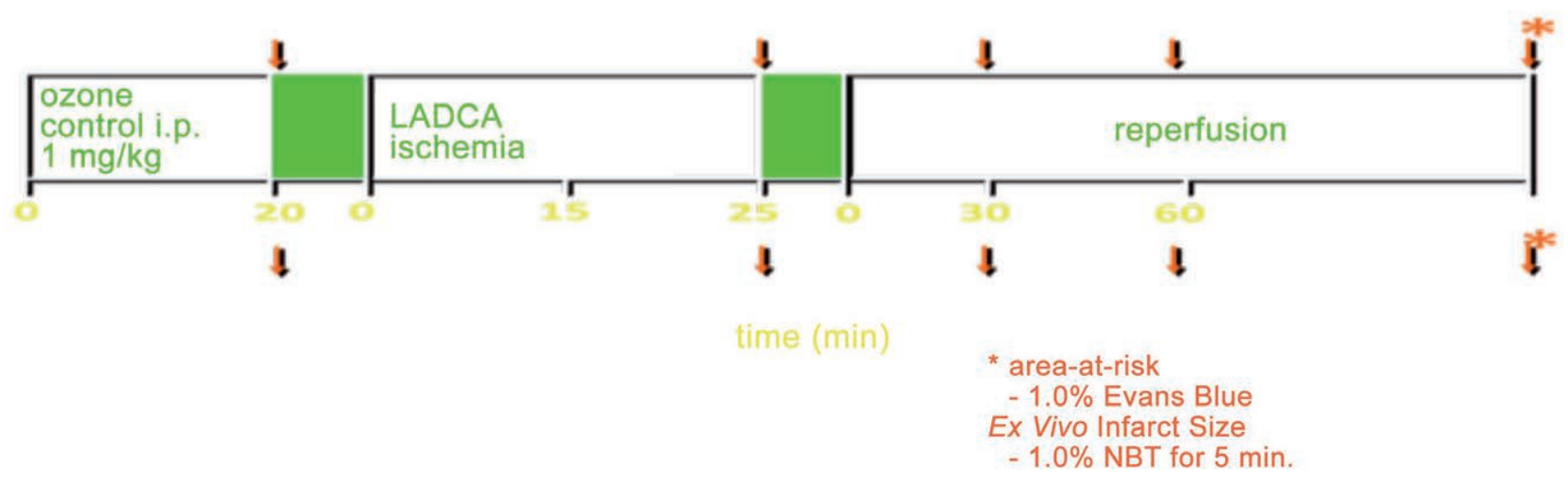

Figure 1. Mean arterial blood pressure recorded at different times. 


\section{Materials and Methods}

Ozone was generated by the MEDICAL 95 CPS Computerized Photometric System manufactured by Multiossigen.

Recruitment criteria were the following: informed consent, patients who presented for observation in the ICU $<6 \mathrm{~h}$ from onset of pain, patients with persistent pain $>30$ minutes who were non-responders to sublingual glyceryl trinitrate.

On the other hand, exclusion criteria were: patients who could benefit from CABG, PTCA or pharmacological thrombolysis, patients with NYHA class IV heart failure, patients who had recently ( $<3$ months) undergone PCI or PTCA.

The $\mathrm{O}_{3}$ group underwent ozonation according to the following regimen: ${ }^{13,14}$ sampling of $200 \mathrm{~mL}$ of blood over 15 minutes in a sterile vacuum blood collection tube containing citrate (ACD); immediate reinfusion of $20 \mathrm{~mL}$ of blood to prevent clotting in the connecting pipe; exposure of $180 \mathrm{~mL}$ of blood to a mixture of $180 \mathrm{~mL} \mathrm{O}_{2}-\mathrm{O}_{3}\left(\mathrm{O}_{3}\right.$ concentration of $30 \mu \mathrm{g} / \mathrm{mL}$ ) for 3 minutes until the blood took on a bright red color; the blood was reinfused following this treatment. After any post-AMI hemodynamic stabilization, treatment was carried out at $6 \mathrm{~h}$, and
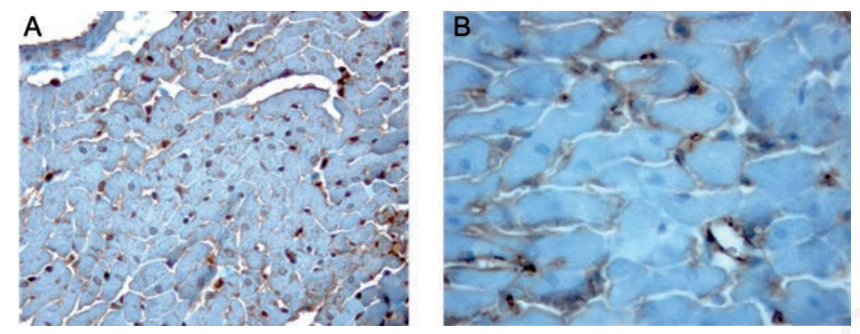

Figure 2. Comparative evaluation of the biological samples of the infarcted myocardial tissue from the control group $v s$ the group of rats.
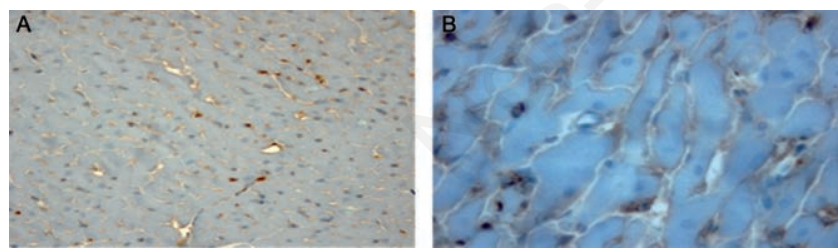

Figure 3. Activity of caspase 3 reduced by pre-treatment with ozone.

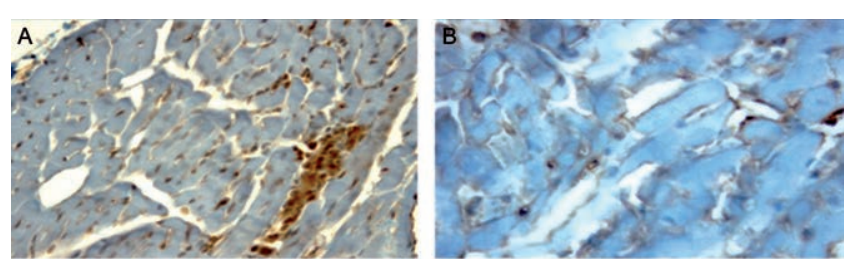

Figure 4. Comparative assessment of the infarcted myocardial tissue from the two groups with regards to macrophage (CD 68) and lymphocyte (CD 4; CD8) activity.
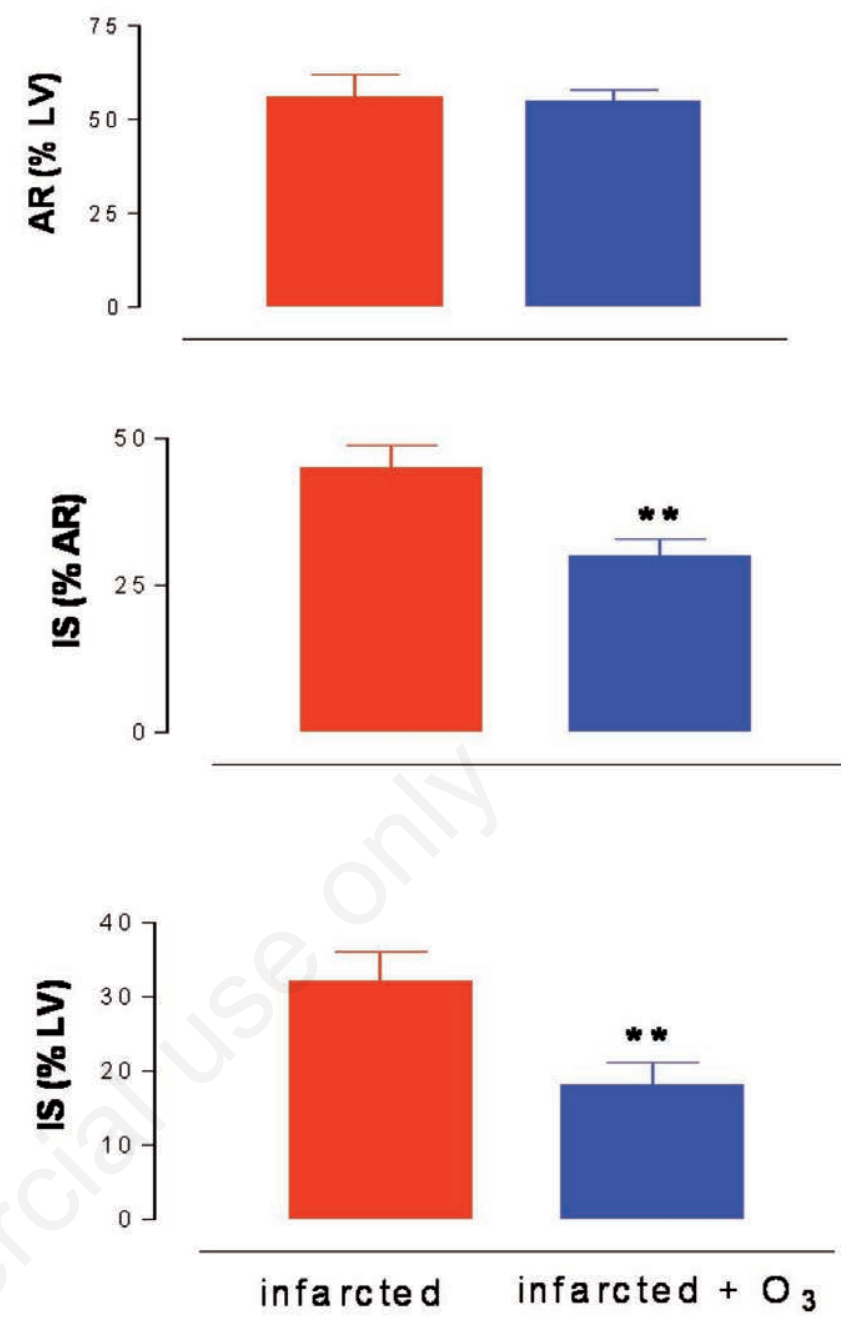

Figure 5. Ozone is capable of significantly reducing infarct extension in mice.

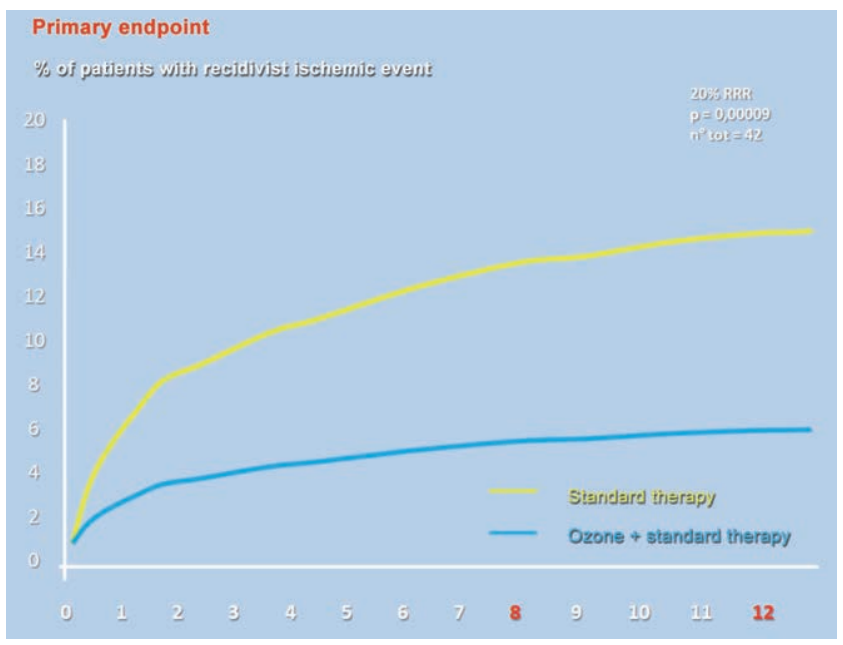

Figure 6. Difference in prognosis tends to increase with the passage of time: at week 12 the gap is significantly enlarged. 


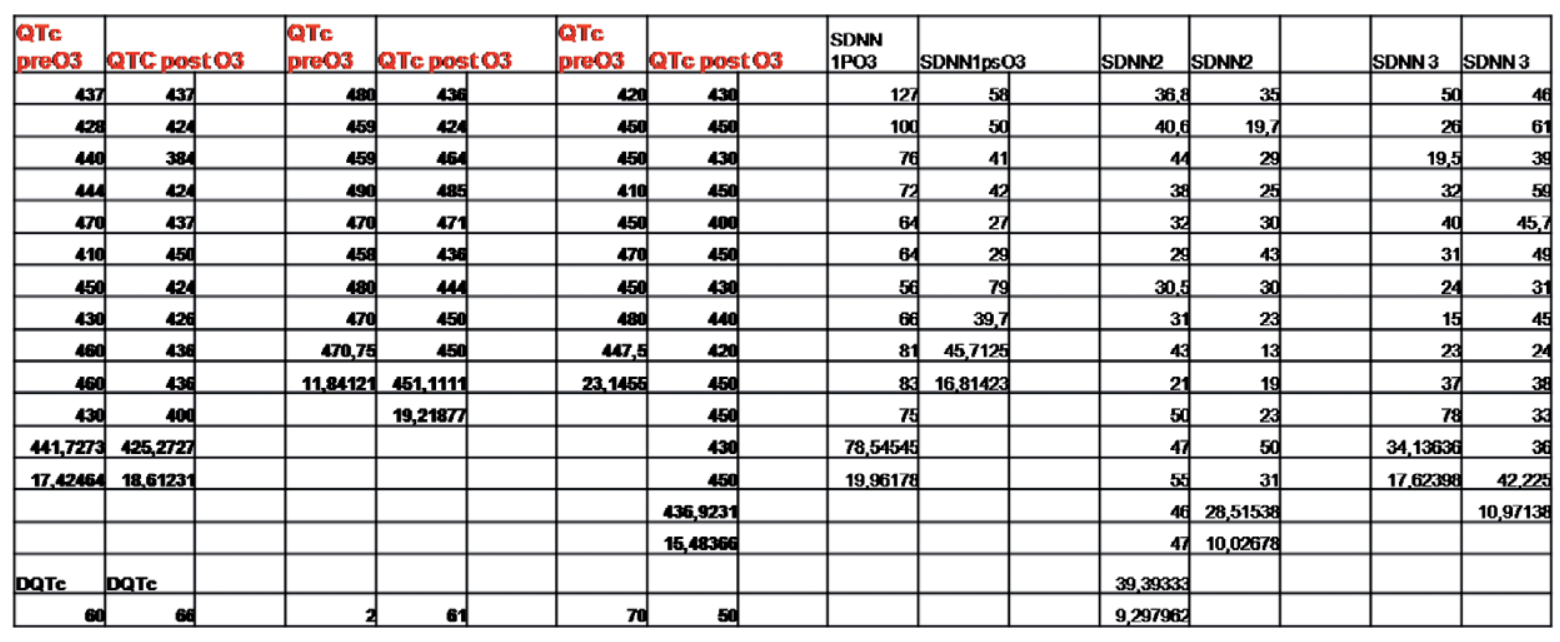

Figure 7. Verification of the secondary endpoint: the QT interval reduces after treatment with ozone.

repeated at 24,48 , and $96 \mathrm{~h}$ from $\mathrm{T}_{0}$ (onset of pain), then the treatments were repeated twice a week for 12 weeks, with clinical and diagnostic tests at 8 and 12 weeks.

\section{Results and Discussion}

It can be seen that in relation to the total number of patients considered (42) that the $\mathrm{O}_{3}$ group, who used ozone therapy in addition to standard therapy, have an RRR of $20 \%$ for recurrent ischemia $\mathrm{P}=0.00009$ vs the $\mathrm{S}$ group who received traditional therapy alone. The diagram also shows that this difference in prognosis tends to increase with the passage of time from week 8 and at week 12 the gap is significantly enlarged (Figure 6). The corresponding myocardial scintigraphy findings with the data recorded at the $12^{\text {th }}$ week show evident recovery of reperfusion in the myocardial tissue. As regards the verification of

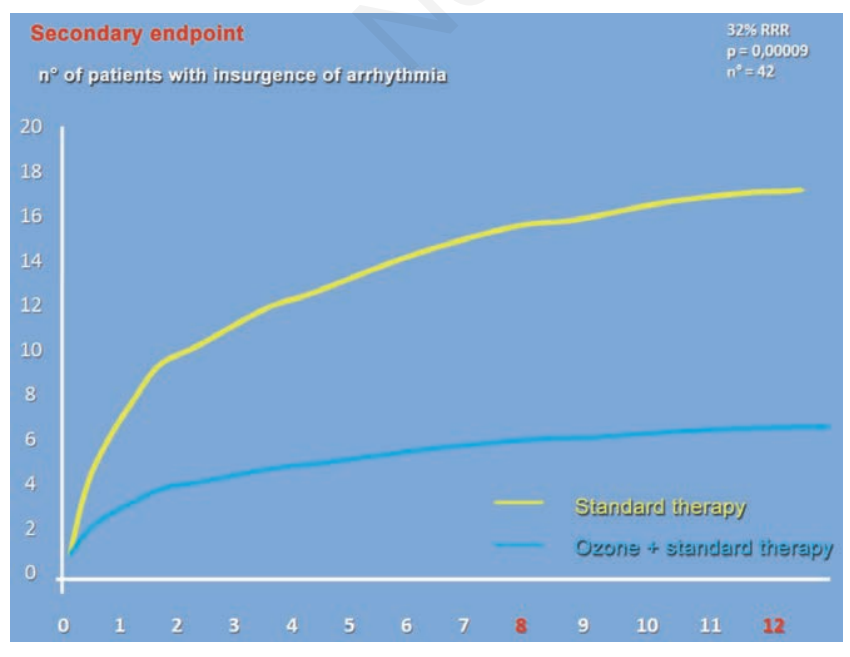

Figure 8. Ozone reduces the relative risk both of ischemic (infarct extension) and arrhythmia complications. the secondary endpoint, the diagram shows that the QT interval reduces after treatment with ozone (Figure 7).

This data prompts the hypothesis that ozone may have a stabilizing effect on the QT interval during the left ventricular recovery phase; this facilitates the eradication of ventricular arrhythmia. The trend is in line with data obtained from induction in rats with a more evident reduction in the RRR of arrhythmia in $32 \%$ of patients; indeed, the graph shows greater widening of the gap with the passage of time (from the $8^{\text {th }}$ to the $12^{\text {th }}$ week).

The limited number of patients investigated does not allow us to pass definitive judgment on the effectiveness of ozone therapy in AMI.

\section{Conclusions}

Ultimately, it is observed that: i) the effectiveness of ozone therapy increases in relation to how early treatment is performed $(<6$ hours from the onset of chest pain) and with its prolongation (the $12^{\text {th }}$ week achieves more effective responses); ii) ozone reduces the relative risk both of ischemic (infarct extension) and arrhythmia complications (Figure 8). ${ }^{15}$

\section{References}

1. D'Elia A, Mingione ML, Ciao A, et al. Role of ozone therapy in the treatment of ischemic heart disease in the acute phase. Faseb $\mathrm{J}$ 2000;2000:1-4.

2. Lettieri B, Chiefari M, Vicario C. [Atti Convegno di Sorrento, 09/10.03.91. Cardiopatie ischemiche ed ozono terapia]. [Proceedings in Italian]. Rome: AIR0 Pubblicazioni; 1991.

3. Torre-Amione G, Anker SD, Bourge RC, et al. Results of a non-specific immunomodulation therapy in chronic heart failure (ACCLAIM trial): a placebo-controlled randomised trial. Lancet 2008;371:228-36.

4. Kyrtsonis MC, Vassilakopoulos TP, Angelopoulou MK, et al. Waldenström's macroglobulinemia: clinical course and prognostic factors in 60 patients. Experience from a single hematology unit. Ann Hematol 2001;80:722-7.

5. Ionescu G, Pitea P, Blaj A. [Ozonoterapia, o noua metoda de trata- 
ment al arteriopatiilor cronice obliterante]. [Article in Rumanian]. Chirurgia 1985;34:3.

6. Valdés AR, Gonzàlez RB, Cepero SM, et al. [Ateroesclerosis obliterante y ozonoterapia. Administración por diferentes vías]. [Article in Spanish]. Angiologia 1993;45:177-9.

7. Valdès AR, Cepero SM, Moraleda MG, Pozo LJ. [La ozonoterapia en los estadios avanzados de la aterosclerosis obliterante]. [Article in Spanish]. Angiologia 1993;45:146-8.

8. Verrazzo G, Coppola L, Luongo C, et al. Hyperbaric oxygen, oxygenozone therapy, and rheological parameter of blood in patients with peripheral occlusive arterial disease. Undersea Hyperb Med 1995; 22:17-22.

9. Bocci V, Travagli V, Zanardi I. May oxygen-ozone therapy improves cardiovascular disorders? Cadiovasc Hematol Disord Drug Target 2009;9:78-85.

10. Mandelzweig L, Battler A, Boyko V, et al. The second Euro Heart Survey on acute coronary syndromes: characteristics, treatment, and outcome of patients with ACS in Europe and the Mediterranean Basin in 2004. Eur Heart J 2006;27:2285-93.
11. Bertrand ME, Simoons ML, Fox KAA, et al. Management of acute coronary syndromes: acute coronary syndromes without persistent ST segment elevation. Recommendations of the Task Force of the European Society of Cardiology. Eur Heart J 2000;21:1406-32.

12. Braunwald E, Antman EM, Beasley JW, et al. ACC/AHA guidelines for the management of patients with unstable angina and non-stsegment elevation myocardial infarction: A report of the american college of cardiology/american heart association task force on practice guidelines (committee on the management of patients with unstable angina). Am Coll Cardiol 2000;36:970-1062.

13. Bocci V. Autohaemotherapy after treatment of blood with ozone. A reappraisal. J Int Med Res 1994;22:131-44.

14. Bocci V. Ozone: a mixed blessing. New mechanisms of the action of ozone on blood cells make ozonated major autohaemotherapy (mah), a rational approach. Forsch Komplementarmed 1996;3: 25-33.

15. Lettieri B. [Efficacia dell'ozono-terapia nella prevenzione della recidiva dell'infarto del miocardio]. [Article in Italian]. Acta Toxicol Ther 1996;17:2-3. 